\title{
Mitochondrial DNA (mtDNA) haplogroups in 1526 unrelated individuals from 11 Departments of Colombia
}

\author{
Juan J. Yunis ${ }^{1,2}$ and Emilio J. Yunis ${ }^{1}$ \\ ${ }^{1}$ Instituto de Genética, Servicios Médicos Yunis Turbay y Cia., Bogotá, DC, Colombia. \\ ${ }^{2}$ Grupo de Identificación Humana e Inmunogenética, Departamento de Patología, \\ Facultad de Medicina e Instituto de Genética, Universidad Nacional de Colombia, Bogotá DC, Colombia.
}

\begin{abstract}
The frequencies of four mitochondrial Native American DNA haplogroups were determined in 1526 unrelated individuals from 11 Departments of Colombia and compared to the frequencies previously obtained for Amerindian and Afro-Colombian populations. Amerindian mtDNA haplogroups ranged from $74 \%$ to $97 \%$. The lowest frequencies were found in Departments on the Caribbean coast and in the Pacific region, where the frequency of AfroColombians is higher, while the highest mtDNA Amerindian haplogroup frequencies were found in Departments that historically have a strong Amerindian heritage. Interestingly, all four mtDNA haplogroups were found in all Departments, in contrast to the complete absence of haplogroup $D$ and high frequencies of haplogroup $A$ in Amerindian populations in the Caribbean region of Colombia. Our results indicate that all four Native American mtDNA haplogroups were widely distributed in Colombia at the time of the Spanish conquest.
\end{abstract}

Keywords: admixture, Colombia, haplogroup, Mestizo, mitochondrial DNA.

Received: October 31, 2012; Accepted: June 16, 2013.

The population of Colombia is predominantly of European origin $(86.1 \%)$, with most individuals being of Spanish descent; other European groups, as well as Arab and Jewish descendants, represent a minor contribution (Yunis et al., 2000b; Rodriguez-Palau et al., 2007). The population of African descent (10.5\%) is distributed mainly in the Pacific and Caribbean coastal regions and islands. The Amerindians ( $3.4 \%)$ are found mainly in the plains, Amazonian jungle and in some regions of the Colombian Andes (Rodriguez-Palau et al., 2007). Different degrees of admixture have been documented in different regions of the country based on blood group analysis (Sandoval et al., 1993). In the Pacific and Caribbean coastal regions there is admixture between those of African and European descent. Amerindian admixture is higher in the southwest and decreases towards the northern section of the Andes, where the European descent component is higher.

Previous mtDNA analysis in Colombian Amerindian populations revealed four distinct haplogroups referred to as A, B, C and D (Mesa et al., 2000; Keyeux et al., 2002; Rodas et al., 2002; Torres et al., 2006; Melton et al., 2007; Rondon et al., 2007). These results have been confirmed by our own study of Amerindian populations (Usme-Romero et al., 2013) that revealed high frequencies of haplogroups

Send correspondence to Juan J. Yunis. Instituto de Genética, Servicios Médicos Yunis Turbay y Cia, Carrera 24 \#42-24, Bogotá, DC, Colombia. E-mail: jjyunisl@unal.edu.co, jjy@yunis.com.co.
$\mathrm{A}$ and $\mathrm{C}$ and lower frequencies of haplogroups $\mathrm{B}$ and $\mathrm{D}$ in northern Colombia, while in the southeast, higher frequencies of haplogroups $\mathrm{D}$ and $\mathrm{C}$ and a lower frequency of haplogroup A were found; we also observed a higher frequency of haplogroup B in western Colombia that declined towards eastern Colombia. In a study of Mestizo populations from the Departments of Cauca and Valle del Cauca, Salas et al. (2008) showed that $94 \%$ of the mtDNA haplogroups were Native American. Rondón et al. (2006), in a sample of Mestizo individuals from Cali in Valle del Cauca, observed that $78 \%$ of the 135 individuals tested carried Amerindian haplogroups. In a study of a non-Amerindian sample from the Department of Antioquia, Mesa et al. (2000) reported that the mtDNA haplogroups were predominantly Amerindian while the Y-chromosome haplotypes were mainly of European origin.

The aim of this study was to use a large sample of the current Colombian population from different Departments of Colombia to confirm that the Colombian mtDNA haplogroups are predominantly of Amerindian origin. The present report represents the largest mtDNA haplogroup study of the non-Amerindian population of Colombia done to date.

We analyzed 1526 archived blood samples from individuals of unrelated maternal lineage. The samples were randomly selected from our database of referrals for paternity testing. Prior informed consent was provided by each individual at the moment of blood collection. In contrast to 
other studies, we did not ask the individuals for "selfreported ancestry" (Caucasian-Mestizo, Amerindian, Afro-descendant, Mulato) since our aim was to verify the previous finding of a sex bias, with the Y-chromosome of European origin and mtDNA of Amerindian origin in present-day Mestizo populations of Colombia (Mesa et al., 2000). The samples were collected in local laboratories in the capitals of 11 Departments of Colombia (Table 1) and then referred to our central laboratory for paternity testing.

DNA was extracted with the DNA Wizard genomic DNA extraction kit (Promega Corporation, Madison, WI, USA), following the manufacturer's recommendations. mtDNA haplogroups were determined after electrophoresis of PCR-RFLP products (haplogroups A, C, D and L) or of undigested PCR products (haplogroup B), according to Parra et al. (1988) (Table 2). Haplogroup L was determined in samples that tested negative for haplogroups A, B, C and D. Samples that did not carry any of the tested haplogroups were classified as "other". Each amplification reaction consisted of $2.5 \mu \mathrm{L}$ of DNA (25-50 ng), $1.25 \mu \mathrm{L}$ of the proper set of primers $(10 \mathrm{nmol} / \mu \mathrm{L}), 2 \mu \mathrm{L}$ of dNTPs $(10 \mathrm{mM})$, $1.5 \mu \mathrm{L}$ of $\mathrm{MgCl}_{2}(25 \mathrm{mM})$ for haplogroup A or $2 \mu \mathrm{L}$ for the other haplogroups, and $0.125 \mu \mathrm{L}$ of DNA Taq polymerase (Promega), in a final volume of $25 \mu \mathrm{L}$. The amplification conditions consisted of a first denaturing step at $94{ }^{\circ} \mathrm{C}$ for $5 \mathrm{~min}$, followed by 34 cycles of denaturing at $94^{\circ} \mathrm{C}$ for $30 \mathrm{~s}$, annealing at $50{ }^{\circ} \mathrm{C}$ (haplogroups $\mathrm{B}$ and $\mathrm{D}$ ) or $55{ }^{\circ} \mathrm{C}$ (haplogroups A and C) for $30 \mathrm{~s}$, extension at $72{ }^{\circ} \mathrm{C}$ for $30 \mathrm{~s}$ and a final extension step at $72{ }^{\circ} \mathrm{C}$ for $5 \mathrm{~min}$. Prior to electrophoresis, $15 \mu \mathrm{L}$ of the amplified products were digested with appropriate restriction enzymes for $3 \mathrm{~h}$ at $37^{\circ} \mathrm{C}$, except for haplogroup B (Table 2). The products were electrophoresed on a 3\% Nusieve/Seakem agarose gel (FMC Corporation, Philadelphia, PA, USA) in $1 \mathrm{X}$ TBE buffer at $100 \mathrm{~V}$ for $1 \mathrm{~h}$, stained with ethidium bromide and photographed. As a control, samples that had been typed for each of the A-D mtDNA haplogroups by restriction enzyme digestion and sequencing of mtDNA HV1 and HV2 regions were always included. The haplogroup frequencies for each population sample were estimated by direct counting.

The mtDNA haplogroups (A, B, C or D) were present in $73.9-96.5 \%$ of the samples tested (Table 1). The lowest Amerindian mtDNA haplogroup frequencies were found in the Departments of Atlántico (73.9\%) and Córdoba/Sucre $(74.8 \%)$ in the Caribbean region of Colombia. The highest frequency was found in Boyacá (96.5\%), followed by Nariño (91.1\%). The mtDNA L haplogroup was most frequent in the Departments of Córdoba/Sucre (25\%) followed by Antioquia (9.6\%), Atlántico (9.3\%) and Valle del Cauca (5.3\%). In all other Departments, the frequencies of this haplogroup were $\leq 3.3 \%$. The highest frequencies of "other" mtDNA haplogroups were found in Atlántico $(16.6 \%)$, Santander (8.6\%), Cundinamarca and Meta (13.3\% each), Valle del Cauca (12.6\%), Norte de Santander
$(8.6 \%)$ and Tolima and Nariño (8\% each). Frequencies $<4 \%$ were found in Boyacá (2.6\%), Córdoba/Sucre (2.7\%) and Antioquia (3.8\%). Overall, haplogroup A was present in $529 / 1526$ individuals $(34.7 \%)$, haplogroup $\mathrm{B}$ in $455 / 1526$ (29.8\%), haplogroup C in 177/1526 (11.6\%) and haplogroup D in 138/1526 (9\%), with an overall Amerindian haplogroup frequency of $85 \%$; haplogroup L occurred in 76/1526 (5\%) and "other" haplogroups, in 151/1526 $(10 \%)$. These results were compared with reports of mtDNA haplogroups in samples of Colombian Mestizos and African descendants described by others (Table 3).

Based on official records (Rodriguez-Palau et al., 2007), the Colombian population is composed of Caucasian descendants $(86.1 \%)$, African-descent Colombians $(10.5 \%)$, Amerindians (3.4\%) and gypsies (0.1\%). Spaniards represent the main Caucasian ancestral population that arrived soon after the discovery of America by Columbus in 1492 (Sandoval et al., 1993; Mesa et al., 2000; Yunis et al., 2000a, 2005a,b; Salas et al., 2008). Other Europeans (German, Italian and French, among others) as well as Arab and Jewish populations have also contributed to the admixture in different regions of present-day Colombia (Yunis et al., 2000a, 2005a). The Spanish conquerors started to populate the Caribbean region, the Andean mountain range and the Pacific region of Colombia soon after their arrival (Salas et al., 2008). The first cities were established in 1510 (Santa Maria Antigua del Darien), 1525 (Santa Marta) and 1533 (Cartagena). Bogotá, the capital of Colombia was founded in 1538 (Salas et al., 2008). Africans started to arrive during the slave trade that began in the 16th century and lasted until the 17th century. The current populations of African descent (10.5\% in present-day Colombia) are distributed mainly in the Pacific and Caribbean coastal regions and islands (Figure 1).

The ancestral Amerindian populations were distributed throughout the country when the Spaniards arrived. Most of the original cultures, such as the Muisca, Quimbaya, Calima, Pijaos and Tayrona that inhabited the Colombian Andes and the Caribbean region no longer exist. During the Spanish conquest and subsequent colonization the original Amerindian populations were enslaved, exterminated or displaced to their current distribution. These Amerindian populations ( $\sim 3.4 \%$ of the current Colombian population) occur mainly in the Amazonian and Orinoquian regions, and at a few locations in the Colombian Andes, Department of Chocó, Sierra Nevada de Santa Marta and Guajira peninsula (Figure 1). During the Spanish conquest and period of colonization, the Mestizo population was formed by the admixture of Amerindians and Spaniards. Admixture between Spaniards and African slaves (Mulatos) occurred in the Caribbean and Pacific regions. Consequently, the resulting pattern of admixture is not homogeneous in Colombia and different degrees of admixture are present in different regions of the country. A study based on blood group markers in a large sample of about 


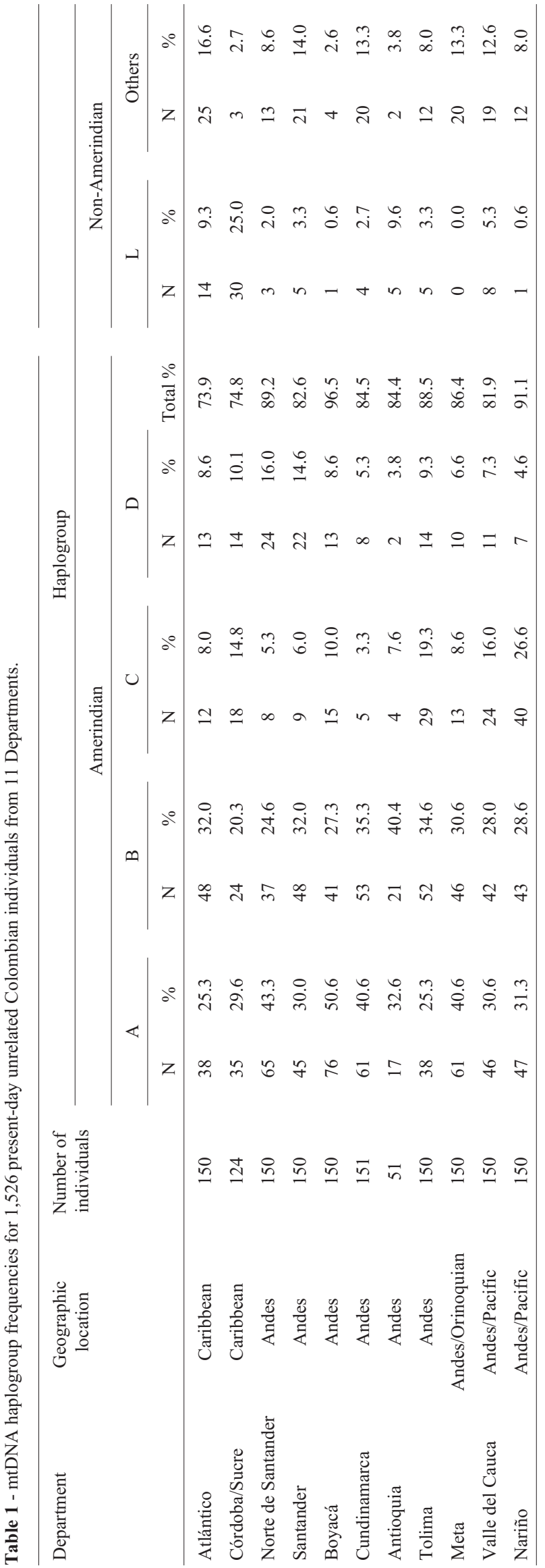

60,000 individuals in Colombia (Sandoval et al., 1993) showed that admixture between individuals of African descent and Mestizos/Caucasians was predominant in the Pacific and Caribbean coastal regions and islands, while Amerindian admixture was higher in the southwest and decreased towards the northern section of the Andes, where the Mestizo component was stronger; the analysis did not include populations living in the Orinoquian and Amazonian regions.

A few studies have examined the mtDNA haplogroups in present-day Colombian populations (Table 3). Carvajal-Carmona et al. (2000) studied 80 individuals from Medellín (Department of Antioquia in the Colombian Andes) and found haplogroup A, B, C and D frequencies of $45 \%, 37 \%, 6 \%$ and $1 \%$, respectively; an overall frequency of $90 \%$ was observed for Native American haplogroups. In another study (Salas et al., 2008), 185 individuals from the Departments of Cauca and Valle del Cauca (Andes/Pacific) were analyzed; 67 of them were "self-classified" as Mestizos, with $94 \%$ of them carrying Native American mtDNA haplogroups (A 40\%, B 13\%, C 34\% and D 7\%). Rondón et al. (2006) reported an overall frequency of $78 \%$ for Native American haplogroups (A 34\%, B 27\%, C 13\%, D 2\% and E 2\%) among 135 mestizo individuals from Cali in the Department of Valle del Cauca. Rodas et al. (2002) analyzed 91 Mestizos from Bogotá and found that $78 \%$ carried Native American haplogroups (A 37.4\%, B 26.4\%, C 7.7\% and D $6.6 \%), 1.1 \%$ carried haplogroup $\mathrm{L}$ and $18.7 \%$ carried "other" mtDNA haplogroups.

The mtDNA haplogroups in Afro-Colombian populations have been determined in a few studies (Rodas et al., 2002; Rondon et al., 2007; Salas et al., 2008). Rodas et al. (2002) studied 159 Afro-Colombians from different locations - 40 individuals from Providencia island, 38 from San Basilio de Palenque (Caribbean coast), 28 from Quibdó (capital of the Department of Chocó), 33 from Nuquí and 20 from Cauca Department. The geographic distribution of these samples means that they have had different admixture histories. In the sample from Providencia (a Colombian island in the Caribbean Sea off the coast of Nicaragua) the frequency of haplogroup L was $52 \%$, that of haplogroup A was $10 \%$ and that of "other" haplogroups was $32.5 \%$. The authors suggested that the L3 haplogroup could be present among the "other" haplotypes and that the total frequency for the L macrohaplogroup would be $82.5 \%$. In the sample from San Basilio de Palenque the frequency of haplogroup $\mathrm{L}$ was $44.7 \%$, haplogroups $\mathrm{A}$ and $\mathrm{B}$ each occurred with a frequency of 5.3\% and the "other" haplogroups had a frequency of $34.5 \%$, with an overall macrohaplogroup L frequency of $76.2 \%$. The populations of Quibdó, Nuquí and Cauca (Pacific region of Colombia) showed somehow different results. In Quibdó, haplogroup L was present only in $21.4 \%$ of the sample; the frequencies of haplogroups A, B, $\mathrm{C}$ and "other" haplogroups were $7.1 \%, 32.1 \%, 3.7 \%$ and $25 \%$, respectively, with an overall frequency of $46 \%$ for 


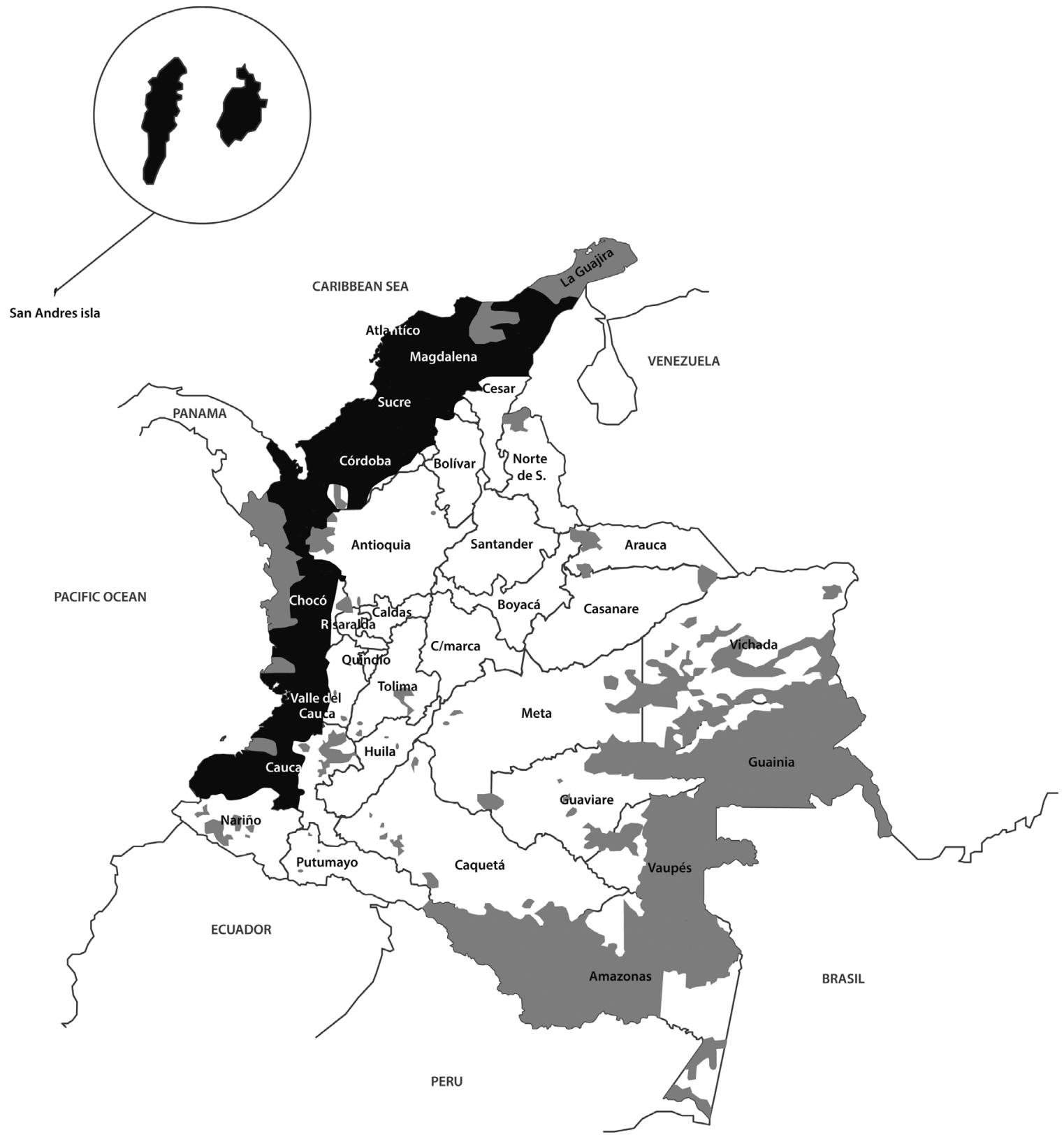

Figure 1 - Geographic location of the Amerindian reservations (gray) and territories with a high frequency of African descendants (black) in Colombia. Inset in the upper left corner shows the San Andres (larger) and Providencia (smaller) Islands in the Caribbean Sea. Modified from Rodriguez-Palau et al. (2007).

Table 2 - Fragment patterns for determining mtDNA haplogroups.

\begin{tabular}{|c|c|c|c|c|c|}
\hline \multirow[t]{3}{*}{ Haplogroup } & \multicolumn{5}{|c|}{ Fragment patterns* } \\
\hline & 663 Hae III & 9 bp deletion & 13259 Hinc II & 5176 Alu I & 3592 Hра I \\
\hline & Primers 577F - 743R & Primers $8195 \mathrm{~F}-8317 \mathrm{R}$ & Primers $13208 \mathrm{~F}-13413 \mathrm{R}$ & Primers 5099F - 5274R & Primers $3457 F-3661 \mathrm{R}$ \\
\hline A & + & - & + & + & - \\
\hline $\mathrm{B}$ & - & + & + & + & - \\
\hline $\mathrm{C}$ & - & - & - & + & - \\
\hline $\mathrm{D}$ & - & - & + & - & - \\
\hline $\mathrm{L}$ & - & - & + & + & + \\
\hline
\end{tabular}

*Parra et al. (1998). (+) present, (-) absent. 


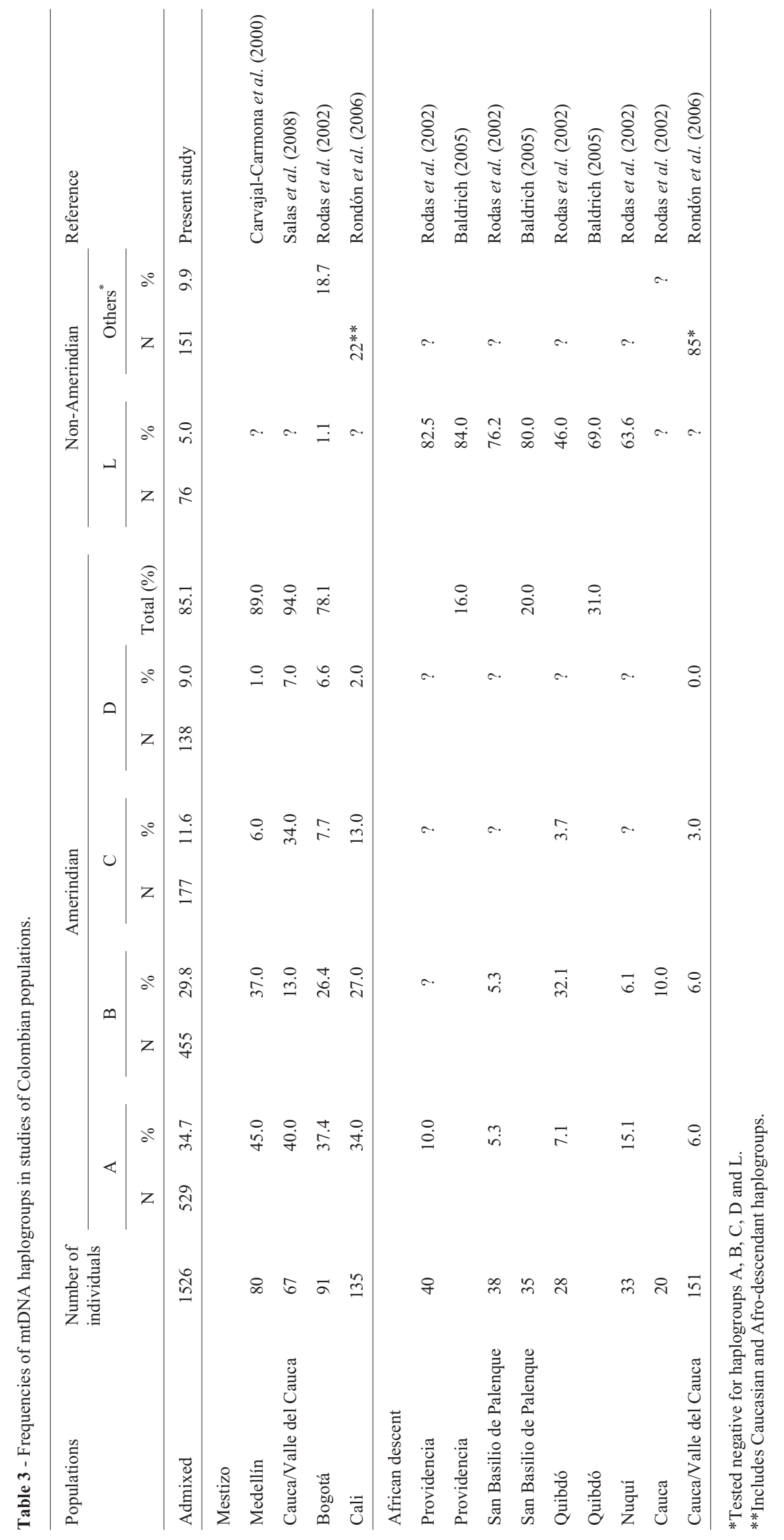


macrohaplogroup L. In Nuquí, haplogroups L, A, B and "other" haplogroups had frequencies of $39.4 \%, 15.1 \%$, $6.1 \%$ and $33.3 \%$, respectively, with an overall macrohaplogroup L frequency of $63.6 \%$. Little can be concluded about the Department of Cauca since only haplogroup B was investigated, with a frequency of $10 \%$.

In a study by Baldrich (2005) based on restriction enzyme digestion and sequencing, 35 individuals from San Basilio de Palenque, 26 from Quibdó and 19 from Providencia were analyzed. Haplogroup L (L1, L2 and L3) was found with frequencies of $80 \%$ in San Basilio de Palenque, $69 \%$ in Quibdó and 84\% in Providencia, the remaining being Amerindian haplogroups with frequencies of $20 \%, 31 \%$ and 16, respectively; no European haplogroups were found. Rondón et al. (2006) reported a frequency of 15\% for Amerindian haplogroups among 151 Afro-descendants in the Departments of Cauca and Valle del Cauca; however, the remaining $85 \%$ haplogroups were not determined. Salas et al. (2008) classified 95 individuals as "Afro-Colombians" and 11 as "Mulatos"; $72.6 \%$ of the African-Colombians carried the haplogroup L and $23.2 \%$ had Native American haplogroups. Among the "Mulatos", haplogroup L was found in $81 \%$ of the individuals. Taken together, these studies indicate that admixture patterns between Afro-Colombians, Caucasian-Mestizos and Amerindians vary considerably in different regions of the country.

Other studies in Colombia have focused mainly on Amerindian populations (Mesa et al., 2000; Keyeux et al., 2002; Torres et al., 2006; Melton et al., 2007). We compared the results obtained in this report with the mtDNA haplogroups found in a sample of 424 unrelated Amerindian individuals from 21 tribes belonging to different linguistic families in present-day Colombia (Usme-Romero et al., 2013). In that sample, the most frequent haplogroup was A (31\%) followed by haplogroups C (30\%), B (22.4\%) and D (13.4\%). Remarkably, present-day Amerindian populations inhabiting the Caribbean region of Colombia did not carry haplogroup $\mathrm{D}$ and showed lower frequencies of haplogroup B (Kogui 0\%, Arhuaco and Chimila 4.8\%, Arsario $12.5 \%$ and Wayuu 17.6\%), while the predominant haplogroup was A followed by haplogroup C. These results contrasted with data obtained for the Departments of Atlántico and Córdoba/Sucre where haplogroup D had frequencies of $8.6 \%$ and $10.1 \%$, respectively, and haplogroup B had frequencies of $32 \%$ and $20.3 \%$, respectively. These results indicate that the Amerindian populations inhabiting the Caribbean region of Colombia at the time of the Spanish conquest carried all four Native American haplogroups and that the admixture that occurred at that time is reflected in the current Mestizo and Mulato populations. The first city built in Colombia during the Spanish conquest was Santa Maria la Antigua del Darién in 1510, later destroyed by the Amerindians in 1524. Present-day Amerindian populations living in geographic proximity to this city include the Embera in the Darién region of Colombia (studied by us and others) and the Zenú (Mesa et al., 2000), who currently speak only Spanish (in the Departments of Córdoba/Sucre). All four haplogroups are present in the Embera tribe studied by us (A 9.5\%, B 52\%, C 28.6\% and D 9.5\%) and are also present in the Zenú community (A 19\%, B 41\%, C $30 \%$ and D 5\%).

The presence of the classic Native American mtDNA haplogroups A, B, C and D in all the Departments of Colombia examined indicates that during the Spanish conquest and period of colonization the Amerindian populations found in the Caribbean, Andean and Pacific regions of Colombia carried all four haplogroups, thus corroborating historical data of female Amerindian admixture with European males. The lowest frequencies of Amerindian mtDNA were found in Departments that historically had an important genetic influx from African populations, with the latter contributing to the admixture process, while the highest frequencies of Amerindian mtDNA haplogroups were found in Departments that historically had a strong Amerindian heritage, such as Nariño and Boyacá.

\section{Acknowledgments}

This research was funded by the Instituto de Genética, Servicios Médicos Yunis Turbay y Cia. and done at this same institute. The authors have no conflict of interest related to this work.

\section{References}

Baldrich R (2005) Profundización en el Studio de Marcadores del DNA Mitochondrial en Poblaciones Afrocolombiana: Contribución al Esclarecimiento de los Orígenes Étnicos de las Poblaciones de Ascendencia Africana. Universidad Nacional de Colombia, Bogotá, 37 pp.

Carvajal-Carmona LG, Soto ID, Pineda N, Ortiz-Barrientos D, Duque C, Ospina-Duque J, McCarthy M, Montoya P, Alvarez VM, Bedoya G, et al. (2000) Strong Amerind/white sex bias and a possible Sephardic contribution among the founders of a population in northwest Colombia. Am J Hum Genet 67:1287-1295.

Keyeux G, Rodas C, Gelvez N and Carter D (2002) Possible migration routes into South America deduced from mitochondrial DNA studies in Colombian Amerindian populations. Am J Hum Genet 74:211-233.

Melton PE, Briceño I, Gómez A, Devor EJ, Bernal JE and Crawford MH (2007) Biological relationship between Central and South American Chibchan speaking populations: Evidence from mtDNA. Am J Phys Anthropol 133:753-770.

Mesa NR, Mondragon MC, Soto ID, Parra MV, Duque C, OrtizBarrientos D, Garcia LF, Velez ID, Bravo ML, Munera JG, et al. (2000) Autosomal, mtDNA, and Y-chromosome diversity in Amerinds: Pre- and post-Columbian patterns of gene flow in South America. Am J Hum Genet 67:12771286.

Rodas C, Gelvez N and Keyeux G (2002) Mitochondrial DNA studies show asymmetrical Amerindian admixture in AfroColombian and Mestizo Populations. Hum Biol 75:13-30. 
Rondon F, Braga Y, Cardenas H and Barreto G (2007) Análisis de la diversidad y el grado de estructura genética presente en poblaciones humanas colombianas a partir del uso de marcadores RFLP de mtDNA. Rev Asoc Colomb Cienc Biol (ACCB) 19:94-103.

Salas A, Acosta A, Alvarez-Iglesias V, Cerezo M, Phillips C, Lareu MV and Carracedo A (2008) The mtDNA ancestry of admixed Colombian populations. Am J Hum Biol 20:584591.

Sandoval C, De la Hoz A and Yunis E (1993) Estructura genética de la población Colombiana. Rev Fac Med Univ Nac Colomb 41:3-14.

Torres MM, Bravi CM, Bortolini MC, Duque C, CallegariJacques S, Ortiz D, Bedoya G, Groot de Restrepo H and Ruiz-Linares A (2006) A revertant of the major founder Native American haplogroup $\mathrm{C}$ common in populations from northern South America. Am J Hum Biol 18:59-65.

Usme-Romero S, Alonso M, Hernandez-Cuervo H, Yunis E and Yunis J (2013) Genetic differences between Chibcha and non-Chibcha speaking tribes based on mitochondrial DNA (mtDNA) haplogroups from 21 Amerindian tribes of Colombia. Genet Mol Biol 36:149-157.

Yunis JJ, Garcia O, Baena A, Arboleda G, Uriarte I and Yunis E (2000a) Population frequency for the short tandem repeat loci D18S849, D3S1744, and D12S1090 in Caucasian-
Mestizo and African descent populations of Colombia. J Forensic Sci 45:429-431.

Yunis JJ, Garcia O, Uriarte I and Yunis EJ (2000b) Population data on 6 short tandem repeat loci in a sample of Caucasian-Mestizos from Colombia. Int J Legal Med 113:175178.

Yunis JJ, Acevedo LE, Campo DS and Yunis EJ (2005a) Population data of Y-STR minimal haplotypes in a sample of Caucasian-Mestizo and African descent individuals of Colombia. Forensic Sci Int 151:307-313.

Yunis JJ, Garcia O, Cuervo AG, Guio E, Pineda CR and Yunis EJ (2005b) Population data for PowerPlex 16 in thirteen Departments and the capital city of Colombia. J Forensic Sci 50:685-702.

\section{Internet Resources}

Rodriguez-Palau E, Hernandez-Romero A, Salamanca-Rodriguez L, Ruiz-García F and Sardi-Perea E (2007) Colombia. Una Nación Multicultural. Dirección de Censos y Demografía. DANE, Departamento Administrativo Nacional de Estadística, Bogotá. http://www.dane.gov.co/files/ censo2005/etnia/sys/colombia_nacion.pdf.

Associate Editor: Angela M. Vianna-Morgante

License information: This is an open-access article distributed under the terms of the Creative Commons Attribution License, which permits unrestricted use, distribution, and reproduction in any medium, provided the original work is properly cited. 